\title{
Field Application of the Slit Type Coastal Structures under Waves and Currents
}

\author{
Sang-Gil Park* •Sug-Jin Kang***Kang-Min Kim*** •Suk-Mun Kim**** • ${ }^{\dagger}$ Joong-Woo Lee \\ *,** Department of Civil and Environmental Engineering, Korea Maritime University \\ *** Seil Enginnering Co., Ltd. \\ **** Buman Construction Co., Ltd. \\ † Department of Civil Engineering, Korea Maritime University \\ \#1,Dongsam-dong, Youngdo-gu, Busan 606-791 Korea
}

\begin{abstract}
Redevelopment of the domestic small fishing ports is being started in earnest by applying the environmentally friendly technology in order to attract tourists. For the purpose of improving water quality in the harbor, selection of breakwater type might have the priority to secure calmness and stability. Therefore, this study is to determine the hydraulic characteristics of reflective ratio, installation efficiency and stability of the special type of blocks through the hydraulic model experiment. The results were introduced to analyze for the effect of infield construction work through numerical analysis. Gujora, a small fishing port in southern Korea, is affected by the waves of SSE, S, SSW direction and strong tidal currents. The results of applying cylindrical slit block show that stability of the blocks and harbor calmness were secured. Considering that the pass rate of a long period wave is still excellent, the primary objective of wave control and the secondary objective of improving water exchange are satisfied simultaneously.
\end{abstract}

Key words : breakwater, Seokmoon block, reflective ratio, hydraulic model, numerical analysis

\section{Introduction}

Application of an environment-friendly technology to redevelopment of domestic small fishery harbor attracting tourists gets on the right track. The traditional breakwater design causes interception or transformation of natural flow within harbor and therefore, the side effect of this shows malfunction in and outside of harbor, such as sand accumulation, ecocide, aggravation of water quality in the harbor, and beach deformation, etc. Then, it becomes the main source of wasting a lot of budgets in bottom dredging in the harbor, water circulation breakwater renovation for water circulation, extension of wharf facilities, and even for construction of alternative fishery harbors for the lost function of the existing harbors. Moreover, it becomes known to the damages to the harbor structures and stability problems to the moored vessels caused by the amplified waves from the reflective structure for the incoming wave. Therefore, in this study, one of the environment-friendly structure developed, so called cylindrical slit block breakwater, is introduced to the coastal waters with a small fishery harbor and wave transformation and water circulation characteristics are analyzed numerically using the results of the hydraulic model experiments for identifying characteristics of the slit type breakwater(Nam, 2010; PNU RCOID, 2010).

\section{Summary of Hydraulic Model Experiments}

\subsection{Prototype Model}

The designed unit block and section view of the prototype breakwater with the use of this unit are shown in Fig.1

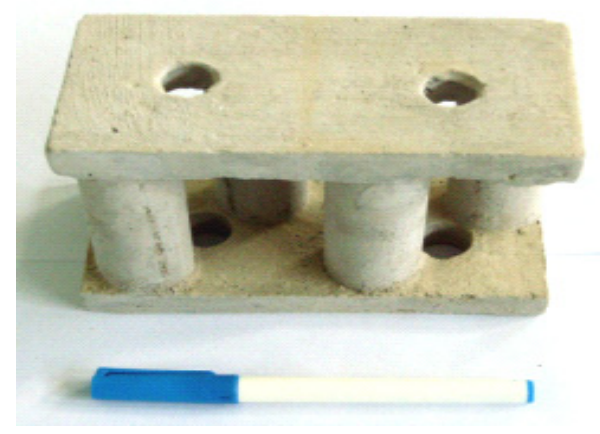

Fig. 1 1:25 Unit block design

\footnotetext{
† Corresponding author, jwlee@.hhu.ac.kr 051)410-4461

* sangila06@hanmail.net 051)410-4460

**ksone77@yahoo.co.kr 051)515-8050

*** kikami@seileng.com 02)840-5182

**** soehowlk@nate.com 055)835-3574

Note) This paper was presented on the subject of "Field Application of the Slit Type Coastal Structures under Waves and Currents" in Asia Navigation Conference 2010 proceedings (In Cheon, KOREA November 4-6, 2010, pp.574-581).
} 
through Fig.3. The prototype model tests were carried out with a geometrical scale of $1 / 25$ (Lee et al, 2009). The linear scale for the model was based on the environmental condition of Samcheonpo and Namhae water area, southeast coast of Korea, at the water depth of $8 \mathrm{~m}$ and approximately highest higher water level of $9.64 \mathrm{~m}$.

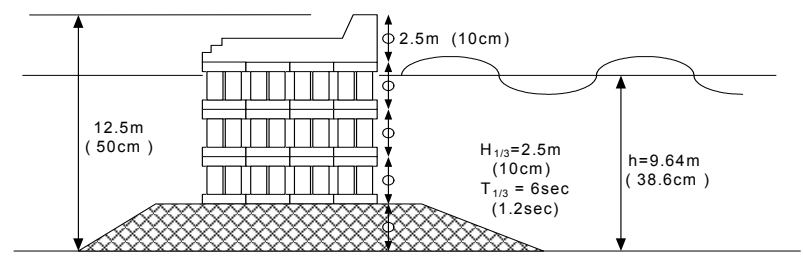

Fig. 2 Prototype of section design

The design wave at the structure was $2.5 \mathrm{~m}$ of height and 6 seconds of period. The reflection and transmission rates from the three different breakwater cases above the riprap mound were shown in Fig.4.

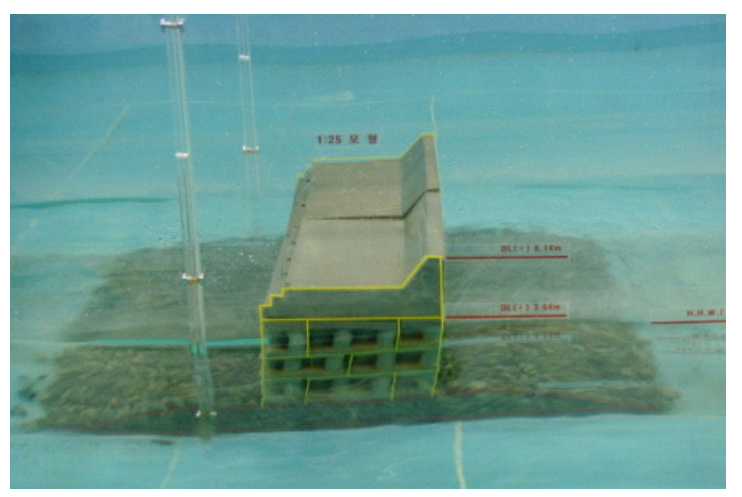

Fig. 3 Prototype model setup

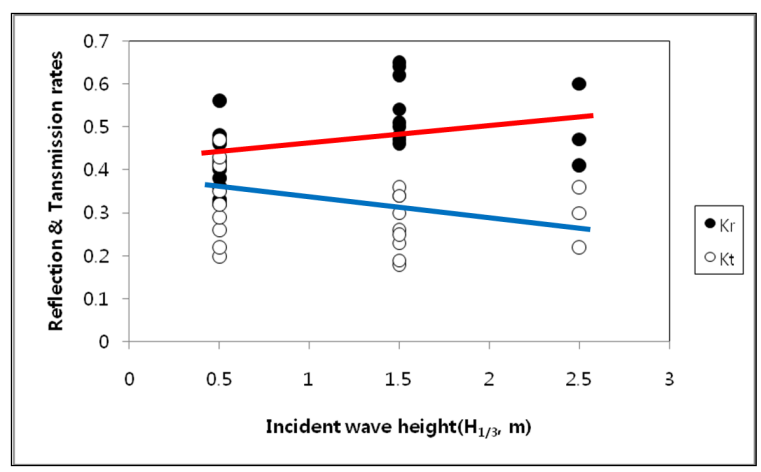

Fig. 4 Comparison of reflection and transmission rates

\subsection{Alternative Design}

The alternative design experiment is shown in Fig.5. The alternative model tests were carried out with a geometrical scale of $1 / 40$. This model was based on the environmental condition of Gujora water area at Goeje Island, southeast coast of Korea, at the water depth of $10 \mathrm{~m}$ and approximately highest higher water level of $2.14 \mathrm{~m}$. The design requirement for wave of the north breakwater was $2.64 \mathrm{~m}$ of height and 16.58 seconds of period. The reflection and transmission rates from the three types of breakwater above the riprap mound were shown in Fig.6.

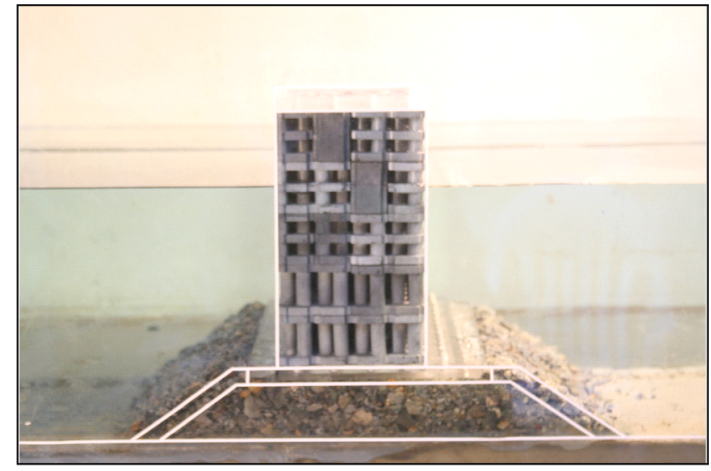

Fig. 5 Alternative model setup

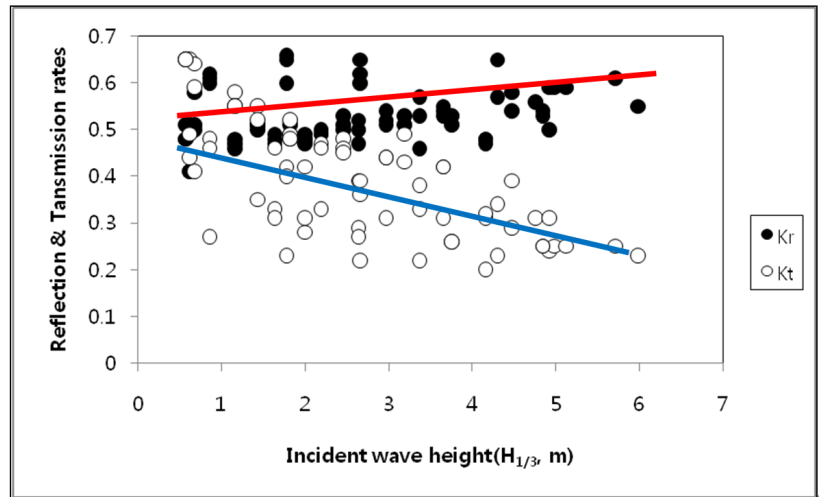

Fig. 6 Comparison of reflection and transmission rates

The reflection and transmission rates from the hydraulic model test results, 0.6 and 0.3 respectively, were introduced to the numerical model experiment to predict the wave transformation, flow patterns, and water exchange effect inside the breakwater.

\section{Numerical Model Experiments}

\subsection{Wave Transformation}

(1) Wave Model Formulation and Conditions

To explicitly simulate the wave transformations in a small fishery harbor and the possible effects of the designed breakwater, a third-generation, numerical nearshore spectral wave transformation model, SWAN, was implemented for this study. This model was developed and validated in the 
previous studies and it also needs the input of the wind data as shown in the similar study completed by Holthuijsen et al. (1989) and Jiang \& Fissel (2008). SWAN can estimate wave transmission through a linear structure such as a slit type breakwater. It is assumed that the breakwater is narrow compared to the grid size. If in reality the width is large compared with grid size, the feature preferably is to be modeled as a bathymetric feature (Booij et al., 1993). Therefore, the model can reasonably account for waves around the breakwater if the directional spectrum of incoming waves is broad. Study area is the Geojedo coastal waters including the Gujora harbor, Korea. This harbor is planned to extend the existing South breakwater and construct a new north breakwater adopting the slit type breakwater. Simulation cases for this harbor are such as CASE A (no structure in north side), CASE B (North B/W by rubble mound structure), and CASE C (North B/W by slit type blocks).

There are several mechanisms for transmission of waves. The transmission coefficient Kt (defined as the ratio of the wave height at the lee side of the breakwater over the wave height at the upwind side) is a function of wave height and the difference in crest level and water level. In this study, it is taken from Goda et al. (1967) such as:

$$
K_{t}=0.5\left(1-\sin \left(\frac{\pi}{2 \alpha}\left(\frac{F}{H_{i}}+\beta\right)\right)\right) \text { for }-\beta-\alpha<\frac{F}{H_{i}}<\alpha-\beta
$$

where $\mathrm{F}=\mathrm{h}-\mathrm{d}$ is the freeboard of the breakwater and where $\mathrm{Hi}$ is the incident wave height at the upwind side of the breakwater, $\mathrm{h}$ is the crest height of the breakwater above the reference, $d$ the mean sea level relative to the reference level, and the coefficients $a, \beta$ depend on the shape of the breakwater, 2.6 and 0.5 for CASE B, 2.2 and 0.4 for CASE C, respectively as Seelig (1979). Depending on the nature of the shore structures and the shape of coastal boundaries the reflected wave field can be more or less scattered. SWAN is able to diffuse the reflection over wave components in different directions. Wave directions of SE, SSE, S as in Table 1 were tested in this study and 50 years set of the frequency for deep water waves of the estimates were used for the wave incident conditions (KORDI, 2005). Meteorological data from 1976 to 2005 (30 years, KMA;
Korea Meteorological Administration, 2006) on the basis of the observed annual maximum wind speed data were analyzed in this location by Gumbel extreme probability model as in Table 2. In this study 50 years return periods of wind data were applied to the wave model. Tide level was applied to the model is Approx.H.H,W which is DL (+) $2.14 \mathrm{~m}$. The area was divided into wide area and narrow area. Wide area wave model was set to $16 \mathrm{~km} \times 16 \mathrm{~km}$ area and it was composed of $25 \mathrm{~m}$ grid spacing. On the other hand, the narrow area wave model was set to $2.0 \mathrm{~km} \times 1.8 \mathrm{~km}$ area and this was set to $5 \mathrm{~m}$ grid spacing.

Table 1 Incident wave condition for design wave

\begin{tabular}{|c|c|c|c|c|}
\hline Direction & Height(m) & Period(sec) & $\begin{array}{c}\text { Return } \\
\text { Period }\end{array}$ & $\begin{array}{c}\text { Grid } \\
\text { Point }\end{array}$ \\
\hline SE & 10.83 & 13.99 & 50 year & \multirow{2}{*}{072126} \\
\hline SSE & 13.66 & 16.43 & 50 year & \\
\hline S & 10.46 & 15.06 & 50 year & 071126 \\
\hline
\end{tabular}

\section{(2) Wave Model Simulation}

The responses of the designs from SE, SSE, S directions of waves to the study area were analyzed in terms of the development cases. Fig.7 through Fig.9 show the wave height contours and Fig.10 through Fig.12 show the wave heights and directions. There was no significant difference for the wave heights between the slit type breakwater and the traditional riprap breakwater in the north breakwater. The wave height distribution in lee side of the slit type breakwater shows less than $0.5 \mathrm{~m}$ and this is also a better design in terms of the tranquility.

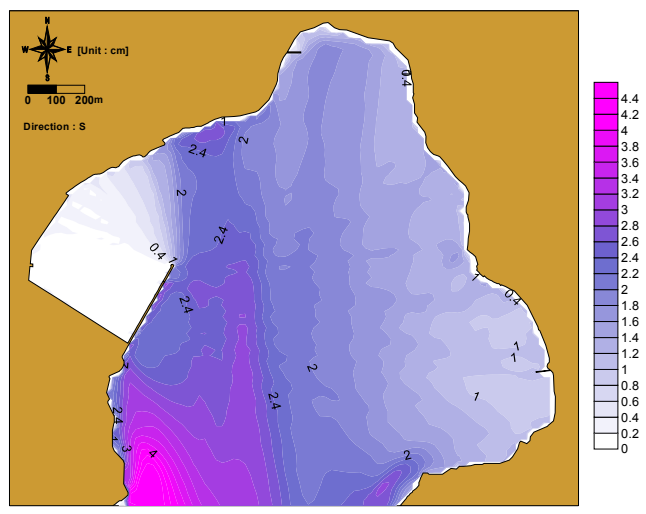

Fig. 7 Wave heights for S (Case A)

Table 2 Characteristics of extreme wind

\begin{tabular}{|c|c|c|c|c|c|c|c|}
\hline Direction & 10years & 20years & 30years & 40years & 50years & 100years & Probability model \\
\hline SE & 12.18 & 13.86 & 14.83 & 15.51 & 16.04 & 17.66 & Gumbel \\
\hline SSE & 10.88 & 12.25 & 13.03 & 13.58 & 14.01 & 15.33 & Gumbel \\
\hline S & 10.58 & 11.94 & 12.72 & 13.27 & 13.7 & 15.01 & Gumbel \\
\hline
\end{tabular}




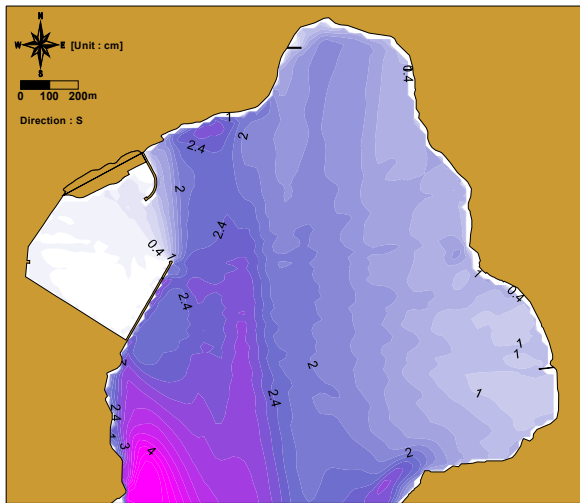

Fig. 8 Wave heights for S (Case B)

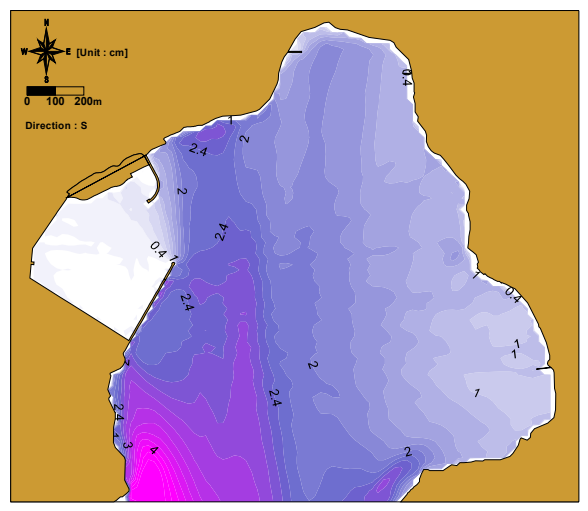

Fig. 9 Wave heights for S (Case C)

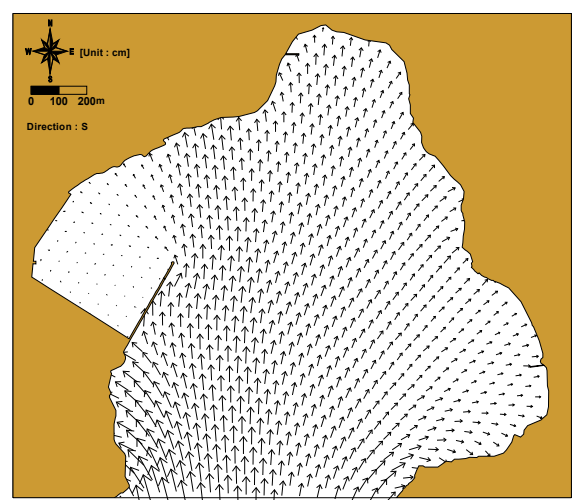

Fig. 10 Wave directions for S(Case A)

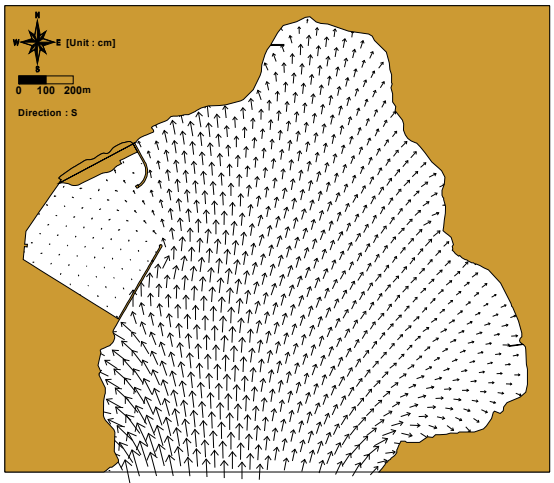

Fig. 11 Wave directions for S(Case B)

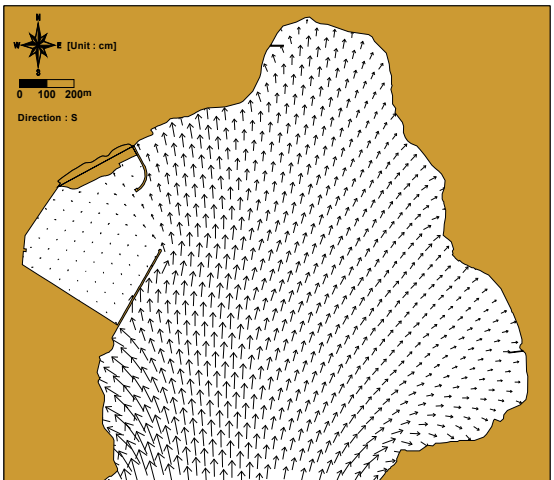

Fig. 12 Wave directions for S(Case C)

Fig. 14 shows the comparison of the wave responses for the selected stations behind the north breakwater.

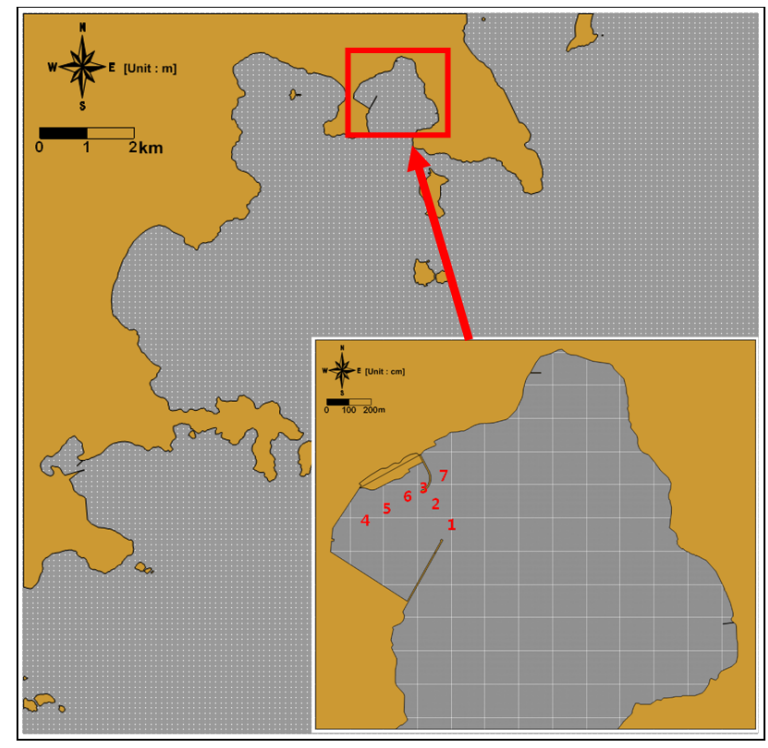

Fig. 13 Variable grids for study area

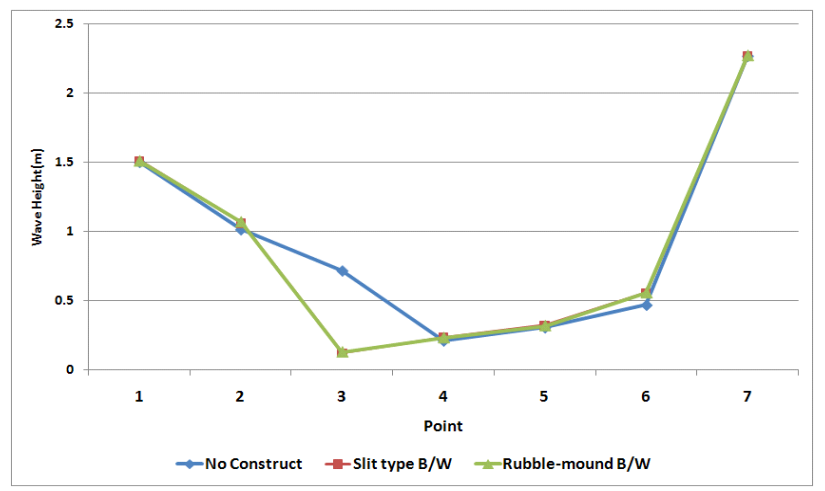

Fig. 14 Wave height inside the harbor(S wave direction)

\subsection{Tidal Currents}

(1) Current Model Formulation and Conditions

Hydrodynamic numerical model used here is the well-known POM (Princeton Ocean Model), which is a 
three-dimensional coastal ocean numerical model. For more detailed description on this model, it should be referred to Blumberg (1977) and Blumberg \& Mellor (1983). Table 3 and Fig.15 are showing that the model setup with the introduced variable grids for both wide and narrow area. Wide area was set to the range of $23.0 \mathrm{~km} \times 16.0 \mathrm{~km}$ including Gujora harbor and the narrow area was set for Gujora harbor area $(2,000 \mathrm{~m}$ $\times 1,800 \mathrm{~m})$. Fig.16 shows the verification of model setup at the selected station inside harbor.

Table 3 Summary of water circulation experiment setup

\begin{tabular}{|c|c|c|}
\hline Division & Wide area & Narrow area \\
\hline Model & \multicolumn{2}{|c|}{ POM(Princeton Ocean Model) } \\
\hline $\begin{array}{c}\text { Model } \\
\text { Range }\end{array}$ & $16.0 \mathrm{~km} \times 23.0 \mathrm{~km}$ & $\begin{array}{c}\text { Gujora Harbor } 2,000 \mathrm{~m} \\
\times 1,800 \mathrm{~m}\end{array}$ \\
\hline Grid & $\begin{array}{c}160 \times 230(36,800), \\
\triangle \mathrm{S}=100 \mathrm{~m}\end{array}$ & $\begin{array}{c}100 \times 110(11,000), \\
\triangle \mathrm{S}=10,20,40 \mathrm{~m}\end{array}$ \\
\hline Conditions & $\begin{array}{c}\text { Input from the Observed tides at Approx.H.H.W, } \\
(\mathrm{M} 2+\mathrm{S} 2+\mathrm{K} 1+\mathrm{O} 1)\end{array}$ \\
\hline $\begin{array}{c}\text { New } \\
\text { structure }\end{array}$ & No construction & $\begin{array}{c}\text { No construction } / \text { North } \\
\mathrm{B} / \mathrm{W} \text { Construction }\end{array}$ \\
\hline
\end{tabular}

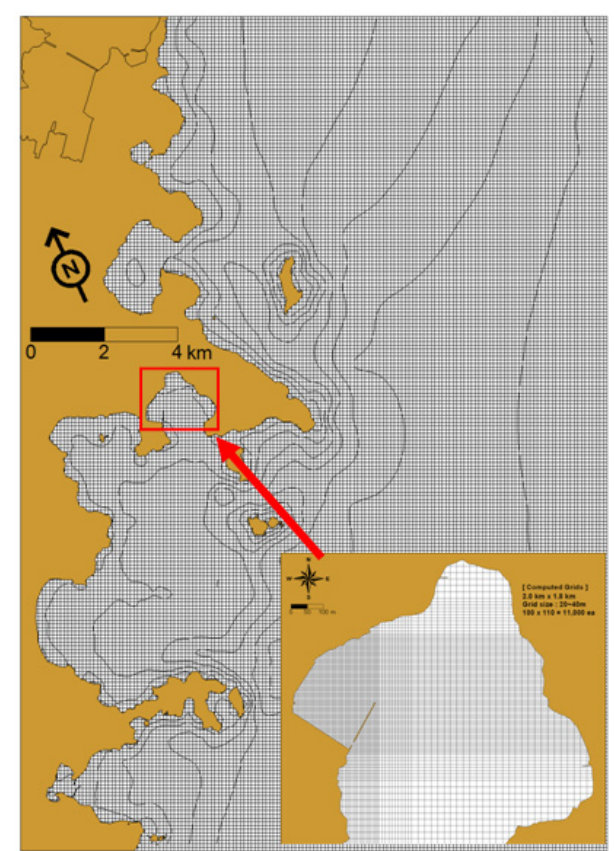

Fig. 15 Variable grids for study area

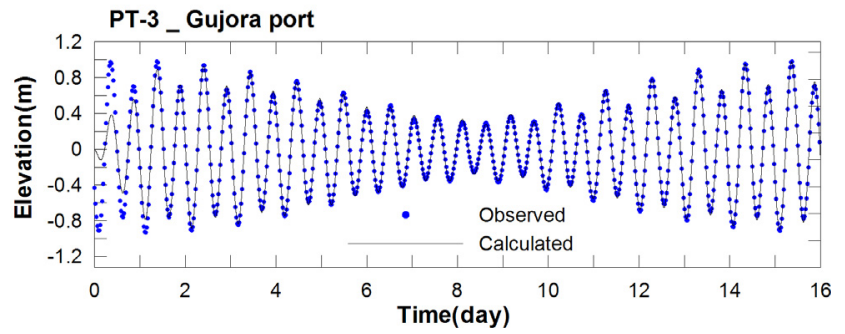

Fig. 16 Verification of model with the tide record inside Gujora harbor

\section{(2) Current Model Simulation}

Narrow models are using the boundary conditions extracted from the wide model calculation. The present case without the north breakwater in the Gujora harbor is showing a very weak current about $2.5 \mathrm{~cm} / \mathrm{s}$ near the south breakwater even in spring tide. The water for Case B was blocked by the breakwater and not smoothly circulating. However, the water for Case $\mathrm{C}$ shows communicating flow patterns in comparison with Case B. Due to the construction of the north breakwater, the increase of current at the gap of two breakwaters, north and south, shows $0.4 \mathrm{~cm} / \mathrm{s}$ for Case $\mathrm{B}$ and $0.3 \mathrm{~cm} / \mathrm{s}$ for Case C. However, the decrease of current also appeared near the north breakwater and shows maximum $0.6 \mathrm{~cm} / \mathrm{s}$ for both cases. These are shown in Fig. 17 through Fig.20. Generally the flow pattern and velocity changes appear limited to the vicinity of the north breakwater but the slit type breakwater case is better for the circulation inside the harbor if we consider a new breakwater.

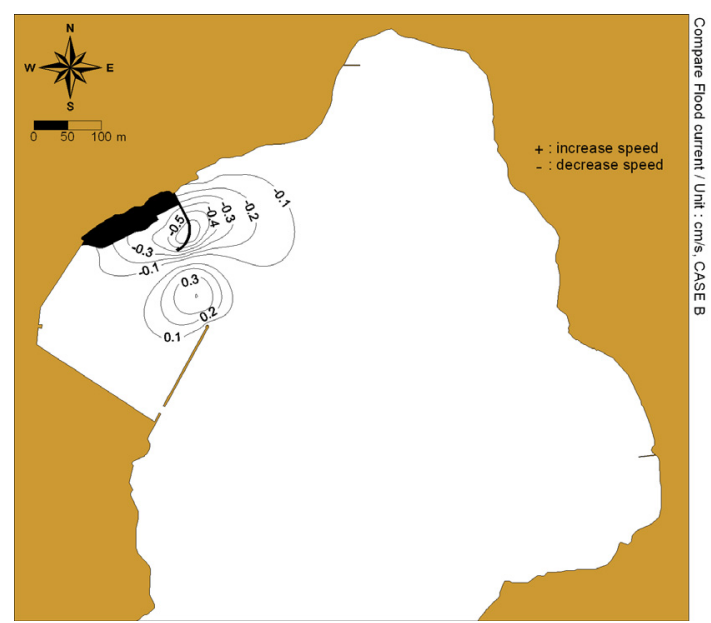

Fig. 17 Max. Flood changes (Case B from Case A)

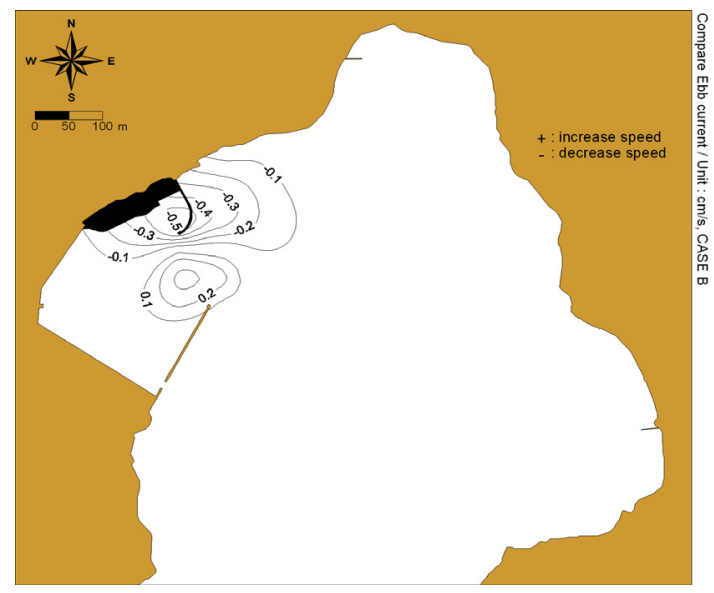

Fig. 18 Max. Ebb changes (Case B from Case A) 


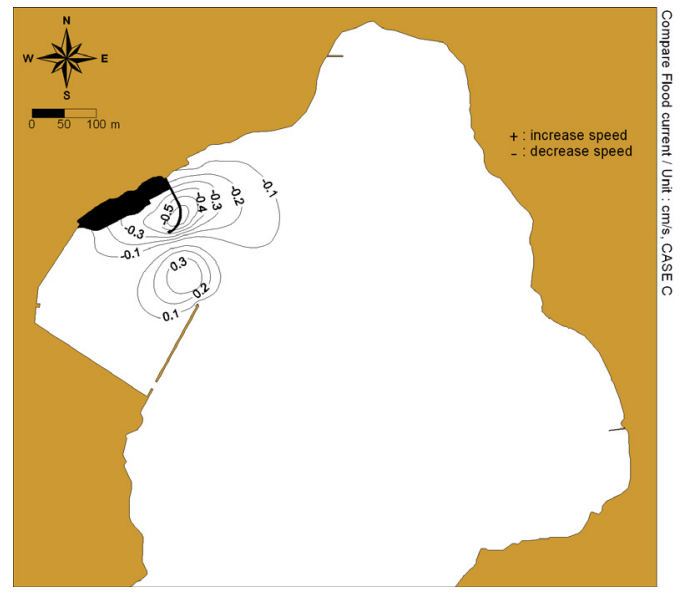

Fig. 19 Max. Flood changes (Case C from Case A)

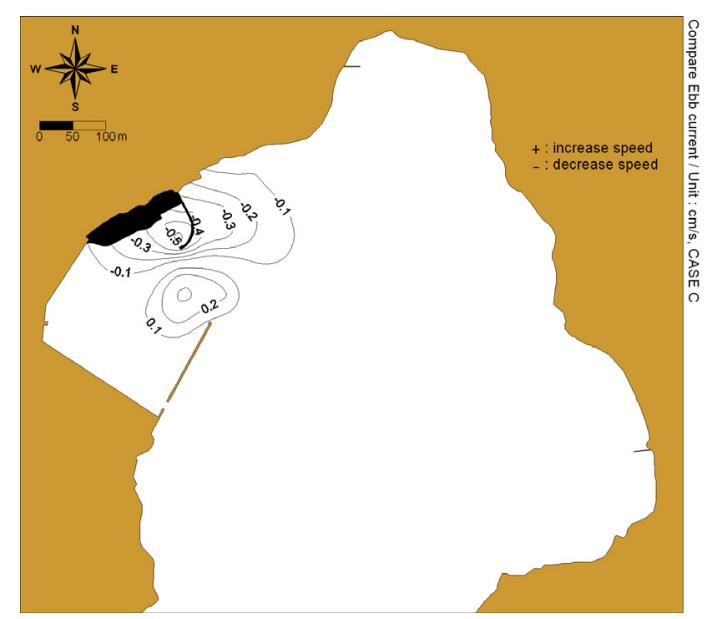

Fig. 20 Max. Ebb changes (Case C from Case A)

\subsection{Water Exchange and SS Tracking}

(1) Water Exchange and Diffusion Model Formulation and Conditions

For the case of the pollutants contained in effluent discharged to waters, the flow is spreaded by advection and diffused by turbulence, and the concentration decay occurs depending on the properties of materials in the process of decomposition and settling down. In order to investigate the spread of these substances, RNDLEE model adopted Random Walk Method (Lee \& Kim, 1995) is applied to the study area. The configuration of this model is as follows. Passive contaminant particles are placed on the flow field is a new position of a particle $X(t+\Delta t)$ in a time $t+\Delta t$ is obtained by the drifting velocity vector, $U$ and the velocity dispersion component, $u^{\prime}$ as follows.

$$
X(t+\Delta t)=X(t)+U \cdot \Delta t+u^{\prime} \cdot \Delta t
$$

In Equation (2) the 3rd term of the right hand side refers to the movement of particles and through the stochastic process it can be expressed as following form.

$$
\begin{aligned}
& u^{\prime} \cdot \Delta t=R \cdot \sigma \\
& \sigma=\sqrt{2 \alpha_{L}\left|u^{\prime}(X(t), t)\right| \cdot \Delta t}
\end{aligned}
$$

Here, $\mathrm{R}$ is a normal distribution which has the mean 0 and the standard deviation 1 and equation (2) is equal to the basic solution of a diffusion equation ignored the advection.

The concentration $C_{i j}$ at grid point $(\mathrm{i}, \mathrm{j})$ in the form of Lagrangian random walk method is represented by

$$
C_{i j}(t)=\frac{M}{N} \frac{n_{i j}(t)}{h_{i j} \Delta x . \Delta y}
$$

Where, $\mathrm{M}$ is the total mass of the contaminant, $\mathrm{N}$ is the total number of injected particles, $n_{i j}$ is the number of particles in the $\operatorname{grid}(\mathrm{i}, \mathrm{j})$ total, $h_{i j}$ is the water depth, and $\mathrm{m}=\mathrm{M} / \mathrm{N}$ is the quantity of contaminant per particle.

Gujora harbor is a natural harbor concaved and surrounded by some islands but handicapped in circulation. In addition, due to the weak current less than $2.5 \mathrm{~cm} / \mathrm{sec}$, it is necessary to consider slit type structure to allow water circulation and protection from the strong wave attack inside the harbor, at the same time. Therefore, this study evaluated the water exchange ratio for both a rubble mound breakwater and a slit type breakwater with the use of two-dimensional particle tracking model and analyzed the particle moving behavior.

The same grid scheme as the current model and the results of flow are used for the water exchange simulation. Water exchange rates were calculated from the particle distribution analyzed from the model. The specification for model simulation is summarized in Table 4. From the behavior of particles, the water exchange rate and detention time which are the evaluation terms and also the impact factors for water quality enhancement. In the beginning, the number of remaining particles within the harbor water area for 15 days (which include the spring, mean and neap tides) was calculated. Water exchange rate is equal to (the initial particle number - the residual particle number) / the initial particle number within the harbor. The calculations were performed with the 180 seconds interval.

Table 4 Summary of water exchange and diffusion experiment setup

\begin{tabular}{|c|l|}
\hline Division & \multicolumn{1}{|c|}{ Contents } \\
\hline Model & $\begin{array}{l}\text { RNDLEE model(Two-dimensional particle } \\
\text { tracking model) }\end{array}$ \\
\hline $\begin{array}{c}\text { Grid size and } \\
\text { Applied Cases }\end{array}$ & Same as the current model \\
\hline $\begin{array}{c}\text { Computation } \\
\text { time }\end{array}$ & $\begin{array}{l}15 \text { days including the neap, mean, and } \\
\text { spring tide (180sec interval) }\end{array}$ \\
\hline $\begin{array}{c}\text { External force } \\
\text { conditions }\end{array}$ & Results from water flow simulation (u, v, $\mathrm{n})$ \\
\hline
\end{tabular}


(2) Water Exchange and Diffusion Model Simulation

Water exchange rates based on the characteristics of particle movement are analyzed. After 15 days, water exchange rate of the current state (Case A) is $95.22 \%$. When the north breakwater is constructed with the rubble mound (Case B), it shows $97.22 \%$, and the case of the slit type breakwater (Case C) is $97.58 \%$. The reason for no significant difference is that there is a weak current, maximum $2.5 \mathrm{~cm} / \mathrm{sec}$ inside harbor. As the source of the contamination is supplied to the area of study by one discharge for the period of 15days in this simulation, it is the lowest case of occurring. However, it is easy to figure out the effectiveness of each case from Fig.21.

Fig.22 24 shows the exchange of water with the slit type breakwater. These figures are for the exchange rate after 1day, 6days, and 15days, respectively. Because the exciting forces are stronger in the period from the spring tide to mean tide, which is shown as 6days figure.

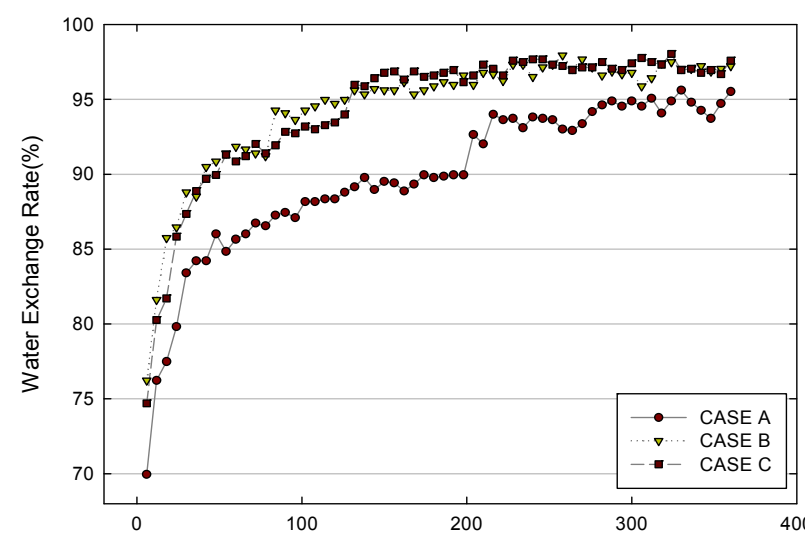

Fig. 21 Comparison of water exchange rates

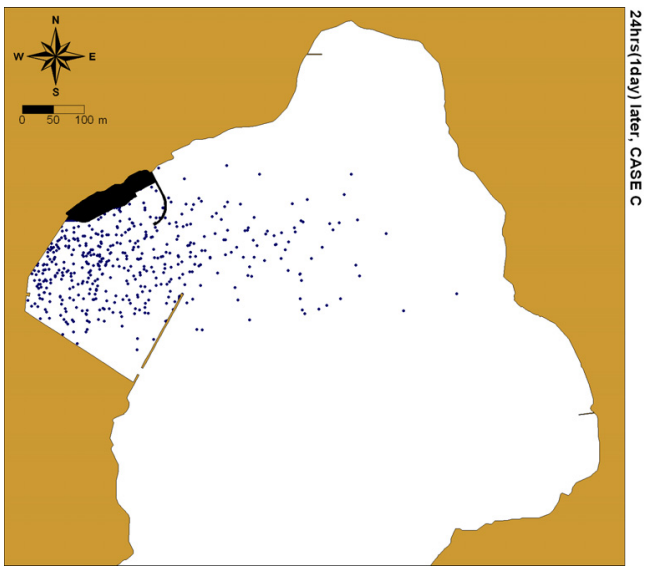

Fig. 22 Particle behavior of case C(24hrs(1day)later)

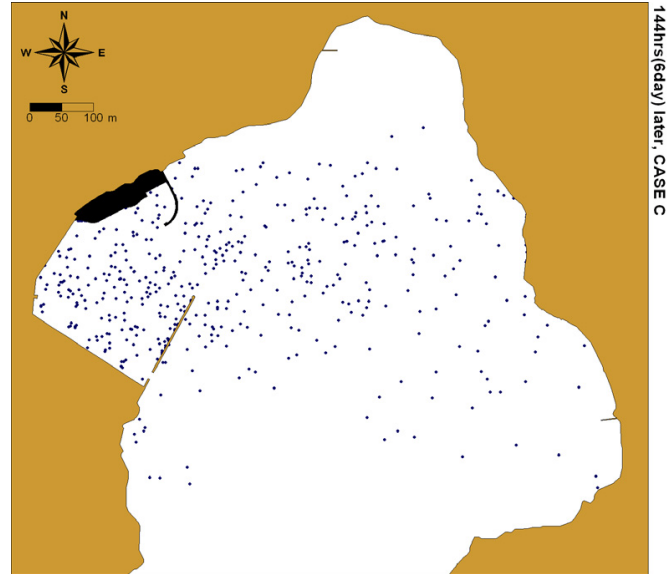

Fig. 23 Particle behavior of case C(144hrs(6day)later)

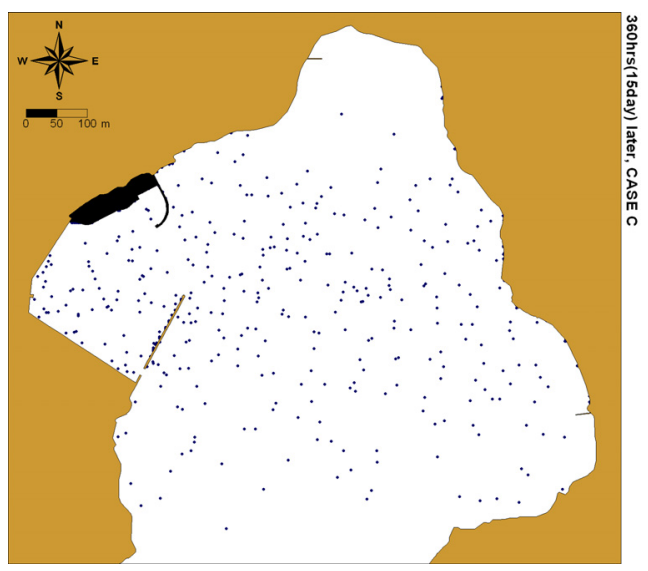

Fig. 24 Particle behavior of case C(360hrs(15day)later)

\section{Conclusion}

In this study the hydraulic model investigation on the design of cylindrical slit type blocks and several section forms of breakwater above rubble mound were summarized first for the numerical model inputs. After this three numerical model simulations for wave transformation, tidal current, and water exchange rates were made to verify the effectiveness of the slit type breakwater, which were applied to a small fishery harbor, together with comparisons for different cases. It was shown that the slit type breakwater is better solution that the rubble mound breakwater for all cases. Although the water exchange ratio has shown small for the design under a single discharge of contamination particles for the period of 15days, the actual phenomena under more severe and violent conditions with the continuous discharge of particle sources would show much improved for the slit type.

Recently, the optimum design of prototype and alternative through a series of studies were successfully applied to the field construction at Seolly beach and Hongheon harbor, 
which are a small beach of Namhae and fishery harbor in the southeast coast of Korea, and these structures were very stable when the typhoon "Ulmu" had attacked to these places this year.

\section{References}

[1] Blumberg, A.F. (1977), Numerical Tidal Model of Chesapeake Bay, J. Hydraulic Division, Vol.103, pp.1-10.

[2] Blumberg, A.F. and G.E. Mellor (1983), A Description of A Three-Dimensional Coastal Ocean Circulation Model, American Geophysical Union (ed. Heaps, N.S.), Washington, D.C., pp.1-16.

[3] Booij, N., L.H. Holthuijsen, and P.H.M. de Lange (1992), The Penetration of Short Crested Waves through a Gap, Proc. 23rd Int. Conf. Coastal Eng, Venice, New York, pp.1044-1052.

[4] Goda, Y., H. Takeda, and Y. Moriya (1967), Laboratory Investigation of Wave Transmission over Breakwaters, Rep. port and Harbour Res. Inst., No.13.

[5] Holthuijsen, L.H., Booij, N., and T.H.C. Herbers (1989), A prediction model for stationary, short-crested waves in shallow water with ambient currents, Coastal Engineering, No.13, pp.23-54.

[6] Jiang, J., and D.B. Fissel(2008), Data on Large Waves and Winds for Victoria International Marina, Technical Report for Victoria International Marina Authority by ASL Environmental Sciences Inc., Canada, 38p.

[7] KORDI (2005), Branches of the Deep Sea Installation Estimate Report II.

[8] KMA (2006), Annual Climatology Report (1976 2005).

[9] Kang, S.W. (2009), Change of Shallow water Design Wave by Interaction of Wave and Ocean Currents, J. Korean Ocean and Coastal Engineering, Vol.21, No.4, pp.307-315.

[10] Nam, K.D. (2010), Experimental Analysis for Development of the Cylindrical Slit Type Breakwater, M.S. Paper, Korea Maritime University.

[11] PNU RCOID (2010), Hydraulic Model Experiment on the Stability Analysis for SeokMoon Slit Type Block.

[12] Seelig, W.N. (1979), Effects of Breakwaters on Waves: Laboratory Tests of Wave Transmission by Overtopping, Proc. Conf. Coastal Structures, Vol.79, No. 2, pp.941-961.

[13] Yoon, S.B. and Liu, P.L.F. (1989), Interaction of Currents and Weakly Nonlinear Waver Waves in Shallow Water, J. Fluid Mech., Vol.205, pp.397-419.
Received 22 November 2010

Revised 8 December 2010

Accepted 9 December 2010 